\title{
Acceptability, feasibility and effectiveness of an eHealth behaviour intervention using self-regulation: 'My Plan'
}

Jolien Plaete ${ }^{\mathrm{a}^{*}}$, Ilse De Bourdeaudhuij ${ }^{\mathrm{a}}$, Maité Verloigne ${ }^{\mathrm{a}}$, Geert Crombez ${ }^{\mathrm{b}}$

a Department of Movement and Sports Sciences, Ghent University, Belgium

b Department of Experimental-Clinical and Health Psychology, Ghent University, Belgium

* Corresponding author at: Ghent University, Department of Movement and

Sports Sciences, Watersportlaan 2, 9000 Gent, Belgium. Tel.: +32 92646363

E-mail address: Jolien.Plaete@UGent.be

\begin{abstract}
Objective: The study aims to evaluate the acceptability, feasibility and effectiveness of the eHealth intervention 'MyPlan', which targets health behaviour in adults.

Methods: Flemish adults were randomly allocated to a control $(\mathrm{n}=155)$, or one of three intervention groups: a physical activity (PA) $(n=158)$, a fruit intake $(n=161)$ or a vegetable intake group $(n=48)$. PA, fruit or vegetable intake were measured at the start and after 1 month.

Results: Adults with low education, and over 40 years evaluated the personal advice and action plans as more motivating, but also the personal advice as too long than adults with high education and younger adults. Overall, $48 \%$ completed the follow-up module after one week, and only $24 \%$ after one month. At one-month follow-up, the fruit intake intervention resulted in more fruit intake $(\mathrm{F}=9.5, \mathrm{p}=0.003)$ and the PA intervention to a higher total physically activity level $(\mathrm{F}=5.6, \mathrm{p}=0.020)$ than the control group. There was not effect for vegetable intake.

Conclusion: 'MyPlan' was feasible and acceptable, and has the potential to increase PA levels, and fruit and vegetable intake.

Practical Implications: Adaptations to the content of the intervention are further needed, and more attention is needed to motivate participants to complete the different follow-up parts.
\end{abstract}

Keywords: physical activity, fruit intake, vegetable intake, computer tailoring, eHealth, self-regulation, goal setting, action planning, feasibility, acceptability, efficacy 


\section{Introduction}

The importance of physical activity (PA) and fruit and vegetable intake to prevent chronic diseases among adults has been well documented[1-3]. To gain health benefits, adults are recommended to perform at least 30 minutes of PA at moderate intensity on most, preferably all days of the week, and to eat 300 grams of vegetables and 3 pieces of fruit every day[4-7]. However, in most developed countries these recommendations are not followed by a large part of the population[4]. In Belgium, only $38 \%$ of the adult population fulfils the health norm for PA, and respectively $38 \%$ and $47 \%$ of the Belgian adults eats fruit and vegetables on a daily base[6,7]. Therefore, interventions that are effective and reach many people are needed.

Computer-tailored interventions are promising to change health behaviour in a large part of the population at a relatively low cost[8-10]. However, the effects of computer-tailored interventions are generally small. There may be many reasons for these results $[9,10]$. One reason may be that these computer-tailored interventions target primarily variables that address the adoption of an intention to change (e.g. attitude or social norm), hence leaving many individuals in an intention-behaviour gap. There are recent calls to address this gap by also addressing post-intentional factors (e.g. action planning and problem solving). A self-regulation perspective may be well suited to integrate both pre- and post-intentional processes, and to develop interventions that guide individuals during all phases of behaviour change[11, 12]. Another reason may be related to the limited feedback provided by early computer-tailored interventions. Most often, tailored feedback is only provided at the very beginning of an intervention, but not further on in the process of behaviour change. Therefore, more dynamic tailoring, meaning a personal feedback on the individual's process of behavioural change on several moments, is recommended[9].

To address these two issues, we developed the eHealth intervention, 'MyPlan', which targets PA levels, fruit intake, or vegetable intake of adults (over 18 years). A self-regulation perspective, was used to target pre-intentional and post-intentional processes, with personal feedback through which awareness was raised, with action planning, problem solving, prompting to self-monitor behaviour, and dynamic tailoring[11, 12]. The latter was achieved by introducing follow-up modules that provided repeated 
feedback and guidance based upon whether and how individuals changed their behaviour and reached their goals.

Developing effective and efficient interventions is a hazardous enterprise, requiring a planful approach and several phases. Pretesting an intervention program is a necessary step[13]. It is important to test whether the intervention is acceptable and feasible for the target population[14]. Therefore, the primary aim was to investigate the acceptability and feasibility of 'MyPlan' in adults. A second aim was to explore differences in feasibility and acceptability between age groups and educational levels. It is often stated that individuals with a lower educational level and older participants are less experienced with computer-based program, and will find these interventions less feasible and acceptable[15]. The third aim was to explore the potential of the intervention in changing behaviour. This was achieved by evaluating the short-term effectivity of 'MyPlan' on PA levels, fruit intake, or vegetable intake. It was expected that PA levels or fruit or vegetable intake would increase if they completed 'MyPlan', whereas PA levels or fruit or vegetable intake would remain stable among adults who did not receive the intervention program (control group).

\section{Methods}

\section{1 eHealth Intervention}

'MyPlan' was programmed in LimeSurvey (LimeSurvey Project Hamburg, Germany. URL http://www.limesurvey.org), a free and open source survey software tool, and is available on the website 'http://www.mijnactieplan.be'. It was developed using models of self-regulation (ref. Maes and Karoly; Schwarzer), and in particular the Health Action Process Approach (ref. Schwarzer). Two sets of behaviour change processes are addressed (a) preintentional processes that lead to a behavioural intention and (b) postintentional processes that lead to actual behavioural change. For each target behaviour (fruit, vegetable or physical activity), there were three modules available.

The first module (T1) addressed both pre- and post-intentional processes. Pre-intentional processes were addressed by the generation of personal feedback to raise awareness and to motivate adults to change their behaviour. Individuals filled in a questionnaire on a particular health behaviour. Based on 
their answers, personal feedback is provided: the personal level of the health behaviour was discussed and compared to health norms. Adults were provided the possibility to read more information about the behaviour (e.g. relation with diseases and health, benefits). This is akin previous computer-tailored programs, and, hence, the content was largely based upon previously developed interventions[16, 17]. Post-intentional processes were addressed by facilitating action planning. Participants were invited to make an action plan to bridge the gap between intentions and behaviour. Adults were guided through action planning by answering questions in the tool. Participants were asked what they wanted to do (e.g. being more physically active by walking), when (e.g. every Monday evening), where (e.g. local park), how long (e.g. 60 minutes) and with whom (e.g. friends). Adults were also offered the possibility to identify difficult situations and hindering factors (i.e. coping planning). This was achieved by selecting the relevant options from a predefined list of hindering factors and barriers. Based on these selections, several solutions were listed and participants could select the solutions that they considered relevant for their situation and wanted to apply. Adults were guided to make an if-then plan (e.g. If it is Monday evening, then I go to the aerobic lessons, in the local gym) (figure 1). Finally, adults were advised on how to selfmonitor their behaviour (e.g. using an agenda) and to pursue their health goals as stated in their action plan. The personal action plan was sent via email, and adults were offered the possibility to send the action plan to family or friends for social support. The content of the action planning tools was partly based upon the work of Vangenugten et al. (2010) and Springvloet et al. (2014), who also applied selfregulation techniques into computer-tailored interventions[18, 19].

[Insert figure 1 (action plan) here]

Module 2 was activated one week after finishing module 1. Participants were contacted by email to revisit the website to complete module 2. In this follow-up module, adults received repeated feedback about their behaviour change process (e.g. ate more or less pieces of fruit compared to last week) and their goals (e.g. did reach the goal to eat 3 pieces of fruit every day). Thereafter, adults had the possibility to adapt their action plan. Adaptations could consist of formulating new goals (e.g. more feasible, or when 
the identified goal was reached, a further goa), or of reconsidering coping plans, based upon the experienced difficulties and barriers during goal pursuit.

Module 3 was activated 1 month after finishing module 1 , and was identical to module 2 . An overview of the whole intervention program is given in figure 2 .

[Insert figure 2 (intervention program) here]

\subsection{Participants and procedure}

Data was collected from February 2014 until April 2014. Participants were recruited by asking adolescents of secondary schools to distribute flyers to adults (e.g. their parents, neighbours, grandparents), by using Facebook and Twitter advertisements, and by recruiting university students. Eligible participants were over 18 years, had a sufficient understanding of the Dutch language, and had access to Internet. Adults were asked to indicate in advance which of the three target behaviours that they wanted to change. Next, participants were invited to visit the website. A computer log in system was used to provide a password to allocate them to either the waiting list control condition, or the intervention condition that targeted their selected health behaviour. Participants from the intervention group had direct access to Module 1 after baseline measurement (T1), and were later invited by email for Module 2 (T2, after one week), and Module 3 (T3, after one month). On average, 25 minutes were needed to complete the questionnaire on demographic info, the behaviour questionnaires, to read the feedback and to make an action plan. After completing the first intervention module, adults were asked to fill in an evaluation questionnaire on the feasibility and acceptability of the intervention. At one-week follow-up (T2), questions were included on the feasibility and acceptability of Module 2. Participants from the wailing list control group did not have access to the three interventions modules. The study was approved by the Ghent University Ethics Committee and an informed consent statement was obtained from each participant.

[Insert figure 3 (flow chart) here] 


\subsection{Measurements}

Socio demographic information (age, educational level) was assessed. Adults with a university or college degree were classified into a 'high education group' and adults with a secondary school degree or lower were classified into a 'low education group'. Adults younger than 40 years were indicated as younger participants, while adults older than 40 years were indicated as older participants[16]. The valid International Physical Activity Questionnaire (IPAQ) was used to assess total PA, moderate-intensity and vigorous-intensity PA for those participants who selected PA as the target behaviour[20]. The frequency (days/week) and duration (min/day) of the different activities were multiplied to express the total PA level per week. By summing all reported physical activities executed at moderate and vigorous intensity, and dividing the sum by seven, the total moderate-intensity and vigorous-intensity PA level per day was obtained[21]. In this study we used total PA, moderate PA and vigorous PA as outcome measures.

To assess fruit intake in those participants who selected fruit intake as target behaviour, the average portion of fruit per day was calculated by using the Flemish 'Fruit Test'[22]. The reported pieces of fruit were multiplied with the correct portion size of the corresponding types of fruit to calculate the average gram per week. To calculate the average portion size of fruit per day, average gram of fruits per week were divided by seven and 125 (= 1 portion size of fruit). In those participants who selected vegetable intake as target behaviour, the average grams of vegetables per day as assessed by the Flemish 'Vegetable test' was used[22]. The reported portions of vegetables were multiplied with the correct portion size of the corresponding vegetable to calculate the average gram per week.

The feasibility and acceptability questionnaire was based on available questionnaires on this topic for adults[16, 23, 24]. Five items were used for the evaluation of the questionnaire, 9 items for the first personalised feedback, 11 items for the action plan, and two items for the if-then plan evaluation (Table 2). Items were measured on a five-point Likert scale; ranging from 'totally not agree' to 'totally agree'.

\subsection{Statistical analyses}


Independent samples t-tests and chi-square tests were conducted to explore baseline differences between the intervention and the waiting list control group for socio demographic and the current level of health behaviour (Table 1). The mean values of the feasibility items and the percentages for interpreting the feasibility were calculated, together with the percentages representing the answers ' 4 ' (agree) and ' 5 ' (totally agree) on the acceptability and feasibility questionnaire items. Independent samples t-tests were used to explore differences in age (younger than or 40 years vs. older than 40 years), education (low vs. high) and selected target behaviour (fruit, vegetables or PA) on acceptability and feasibility items. Repeated measure ANOVAs, with time (baseline (T1) and 1-month follow-up (T3)) as within-subjects factor and condition as between-subjects factor, were executed on completed data to analyse the effect of 'MyPlan' for the selected target behaviour. Separate analyses were conducted for fruit intake, vegetable intake and PA. The outcome variables were first checked for normality by plotting a normal score plot. All outcome variables were log-transformed for analyses to improve normal distribution. For ease of interpretation, back-transformed mean values are reported in the tables. Analyses were controlled for baseline values of PA, FV intake, age and educational level. Statistical significance was set at a level of 0.05, P-values between 0.05 and 0.1 were considered borderline significant. All analyses were executed with SPSS 21.0.

\section{Results}

\subsection{Baseline characteristics}

In the intervention condition, 225 participants started the intervention module for fruit, 84 for vegetables and 267 for PA. In the control group, 201 participants started the questionnaire (See flow chart in figure 1). In total, 194 of the 367 participants who completed the first intervention module for one of the three behaviours (vegetables, fruit or PA) also filled in the acceptability and feasibility questionnaire about Module 1. Acceptability and feasibility questions about Module 2 were filled in by 235 of the 367 participants. Table 1 presents the baseline characteristics for the sample that completed the target behaviour questionnaire at baseline (T1) and the significant differences regarding demographics and 
behaviour between the intervention and control condition. In total, $48 \%$ completed module 2 and $24 \%$ module 3.

[Insert table 1 here]

\subsection{Evaluation of the eHealth intervention}

\subsubsection{Module 1}

The total mean scores (range 0-4) for most items about module 1 were good (higher than score 2)(Table

2). The majority of the participants indicated (agreed to totally agreed) that the questions were easy to understand (96.9\%), had clear answering options (91.6\%) and had clear instructions (96.4\%). About $11.5 \%$ indicated that these questions were too long and $5.8 \%$ found that there were too many questions. Most adults thought that the personal feedback was relevant (84.5\%), interesting $(79.1 \%)$, clear (83.3\%) and understandable (59.5\%). A majority found that the advice was instructive $(61.1 \%)$ and motivating (59.5\%). Only $5.9 \%$ found the personal feedback too long, and $10.3 \%$ indicated the advice to be too prescriptive. Participants who read extra information $(n=26 ; 13,4 \%)$ found it positive that they could choose which information they wanted to read. The extra information was evaluated as useful by $84.6 \%$ of these participants. Most participants thought that the program contained good questions $(85.7 \%)$ and tips (77.4\%) to make an action plan. A large part of the participants indicated that the plan had an attractive lay-out(71.0\%), was easy to understand (93.4\%), personally relevant (76.3\%) and extra motivating $(61.5 \%)$. The majority of the participants had the intention to live up to the plan (86.3\%). Only $36.2 \%$ had the intention to print their action plan. Most participants found it positive that they could make an if-then plan $(70.7 \%)$ and $89.5 \%$ indicated to have enough information to make such a plan. Some significant differences in acceptance and feasibility of Module 1 were found as a function of age groups, educational level and behavioural target(Table 2).

[Insert table 2 here] 
Younger participants $(<40 \mathrm{y})$ found the answer options of the questionnaire more clear than older participants $(>40 \mathrm{y})[\mathrm{t}(187)=1.95, \mathrm{p}<0.05]$. However, older participants reported more that the personal advice was interesting and instructive[t(182)=-2.50, $\mathrm{p}<0.05 ; \mathrm{t}(181)=-2.75, \mathrm{p}<0.01]$. Older participants also found more that the action plan was extra motivating[t(181)=-3.75, $\mathrm{p}<0.001]$. Participants with higher education reported more that the questions were easy to understand compared to participants with lower education[t(187)=-2.09, $\mathrm{p}<0.05]$. Those with lower education indicated more that the personal advice was too long $[\mathrm{t}(181)=-1.71, \mathrm{p}<0.10]$. However, lower educated participants found the personal advice more instructive $[\mathrm{t}(181)=1.98, \mathrm{p}<0.05]$ and motivating compared to higher educated participants $[\mathrm{t}(181)=1.84, \mathrm{p}<0.10]$. Furthermore, the low educated group reported more that the action plan included all necessary things and indicated more that the lay-out was attractive than participants with higher education $[\mathrm{t}(179)=2.44, \mathrm{p}<0.05 ; \mathrm{t}(179)=2.45, \mathrm{p}<0.05]$. Participants who completed the PA module, indicated more that there were too many questions compared to those that completed the fruit module. Participants who chose fruit, found the action plan more motivating than those who chose PA. More participants indicated to live up to their plan for fruit compared to participants that had a plan for PA. No differences were found for vegetables compared to fruit or PA.

\subsubsection{Modules 2 and 3}

There was a high dropout for module 2 and 3 for all conditions. For fruit only 35\% participants completed the assessment at T3, for vegetables 14\%, and for PA 17\%. In the control condition 27\% (See flow chart in figure 3). Of the 235 adults that answered the acceptability and feasibility questions about module 2 , 48.7\% obtained their goal. Most adults(84.3\%) found it positive that they could evaluate whether they reached their goals, and indicated that this evaluation is extra motivating $(68.1 \%)$. About $25 \%$ of the participants reported that they had searched for social support by sending their action plan to someone else. Of these participants, $64.9 \%$ indicated that they were supported by the ones who received their action plan. Goals were self-monitored by $38.7 \%$ of the participants. No significant differences were found in the acceptability and feasibility questions about module 2 as a function of age and educational level. 
However, a significant association was found between age and printing the action plan, between age and monitoring goals and between the choice of behaviour and reaching goals. Participants younger than 40 years, printed their action plan more and also monitored more their behaviour compared to older participants $\left[\chi^{2}(234)=2.7, \mathrm{p}<0.10 ; \chi^{2}(234)=9.5, \mathrm{p}<0.05\right]$. Participants who made an action plan for vegetables or fruit reached their goal more than those who made an action plan for PA $\left[\chi^{2}(203=6.1, p<\right.$ $0.05]$.

[Insert table 3 here]

\subsection{Intervention Effects on PA, fruit intake or vegetable intake}

The mean values of the self-reported fruit intake, vegetable intake and PA on baseline (T1) and one-month follow-up (T3) of the complete cases per condition are shown in table 4. Fruit intake $(\mathrm{F}=9.5, \mathrm{p}=0.003)$ and total $\mathrm{PA}(\mathrm{F}=5.6, \mathrm{p}=0.020)$ increased stronger from baseline to follow up in the intervention group compared to the control group (groupxtime interactions). The intervention group had a stronger increase than the control group. Borderline effects of the intervention were found for vegetable intake $(\mathrm{F}=3.0$, $\mathrm{p}=0.089)$ and moderate intensity $\mathrm{PA}(\mathrm{F}=2.9, \mathrm{p}=0.092)$. No significant interaction effect was found for vigorous PA.

[Insert table 4 here]

\section{Discussion and conclusion}

\subsection{Discussion}

This study evaluated the acceptability and feasibility of the eHealth intervention 'MyPlan', as well as its potential to promote health behaviour. "My Plan" was developed using a self-regulation framework, and integrated tools to address pre-intentional and postintentional processes. The results can readily be summarized. First, the questionnaires to assess health behaviour and on which the personal feedback was based, were evaluated as understandable and as including clear answering options and instructions. Second, a large majority reported the personal feedback as personally relevant $(84,5 \%)$, which is 
substantially larger than in previous studies (Vandelanotte et al., 2003: 53,8\%)[16]. Only a small percentage reported the personal advice to be too directive. Third, the action plan was experienced as interesting, instructive, motivating. Fourth, participants with older age and low educational status did not experience the intervention as less acceptable or feasible. The opposite was rather the case. Nevertheless, there are some issues that warrant attention and will be discussed later. Fifth, the intervention proved to be able to increase PA, and fruit intake in the short term (after one month), but there was only a borderline effect for vegetable intake.

Although the intervention was found overall feasible and acceptable, there some issues that warrant attention. Low educated individuals did found the questions used to guide action planning less easy to understand, and found the personal advice as too long, compared to high educated individuals. Older participants found the answer options less clear than younger participants. Of further note is that participants from the PA intervention reported that there were too many questions, probably owing to the large number of items in the IPAQ. In further adaptations of 'MyPlan' these issues will be taking into account. Shorter questions will be used. In the personal advice, pictures, symbols and short slogans will be added[15]. The use of the short version of the IPAQ may be considered, but this will come along with a cost as domain specific estimates of PA can then not be estimated.

There were some marked differences between the interventions groups. It seems like the PA intervention was more difficult than the vegetable or fruit intervention. In the PA intervention the action plan was rated as less motivating and participants were less inclined to live up to their plan. Although the majority in the PA intervention group had the intention to live up to their plan, only half reached their goals, which is lower than for the fruit and vegetable intervention groups. It may well be that changing PA levels is more difficult than changing fruit intake, since changing PA is a complex behaviour to initiate and maintain[25].

Possible reasons for not living up to the plan can be that participants had no intention to live up to their action plan yet, were not able to change their behaviour, time was too short or goals were too 
difficult to reach. Therefore, it should be evaluated if goals are reached and/or adapted after a longer time period.

Only a small group sent their action plan for social support. Those who did, indicated to be supported. Sharing action plans with others seems not to be a preferred technique. Further research is needed to unravel the reasons why participants do not search for social support and how social support in eHealth tools can be improved in other ways than sending an email. Of particular note is the observation that only a small number of participants followed up the suggestion/advice to monitor their behaviour, although research has identified this technique as one of the most effective to change behaviour[26]. Future researchers may integrate various monitoring tools into interventions, from which the participants may select the most doable.

There was a notable large drop-out in our study. Our intervention did contain techniques that have been proposed to enhance sustained use (i.e. goal setting, self-monitoring of behaviour). This is a challenge for many computer-tailored or internet intervention[27, 28], and will need to be addressed to use the full potential of eHealth interventions. Perhaps, time needed (e.g. on average 25 minutes) to complete the first module was too long, or instructions to revisit the website and ways to get access to the follow-up modules were not clear. We only used one email to invite adults to revisit the website. In the future, we may use emails with updated information and an email and SMS reminder system[28]. Another possibility, which was considered from the outset of the design of 'MyPlan', is to implement in settings which may provide face to face support by peers or counsellors[28, 29]. The basic idea is to implement MyPlan in general practice settings. General practitioners (GPs), are likely to be influential because of their credibility, and they can provide personal support during computer-tailored interventions[30-32].

The potential of the eHealth intervention to change behaviour is promising. There were improvement in PA and fruit intake, and the effect on vegetable intake was borderline significant. There are important limitations to consider. We only used self-reports to assess intervention effects which may have led to demand effects and inaccurate responses[33]. Furthermore, the effect could only be evaluated in a small 
group who completed all parts of the eHealth intervention, due to a high drop-out at follow-up. Also, to assess the long-term impact of the intervention a longer trial is needed.

\subsection{Conclusion}

'MyPlan' was evaluated as feasible and acceptable, even by older (>40y) and low educated adults. Despite a good feasibility evaluation of the different intervention parts (i.e. personal feedback, action and coping planning tool), the high drop-out indicated that more effort is needed to increase feasibility and sustained use of follow-up modules. Promising short-term results for the effectiveness of 'MyPlan' in increasing physical activity levels and fruit and vegetable intake were revealed.

\subsection{Practical implications}

'MyPlan' can be further used in adults, also older (>40y) and low educated adults. Adults should however be motivated more to revisit the intervention follow-up modules by using emails with updated information and an email and SMS reminder system. Also, short intervention programs with clear instructions and easy access to revisit the website should be used. Furthermore, an integrated tool for self-monitoring of behaviour and other ways to integrate social support are needed. Finally, it is also important to investigate the long-term impact of eHealth interventions in a longer trial.

\section{Authors' contributions}

JP conducted the data collection, statistical analyses and drafted the manuscript. MV participated in the data analyses and revised the manuscript. IDB and GC helped to draft the manuscript and revised the manuscript for important intellectual content. All authors read and approved the manuscript and declare that they have no competing interests'.

\section{Acknowledgements}

The study was commissioned, financed and steered by the Ministry of the Flemish Community, Department of Welfare, Public Health and Family. Maïté Verloigne is supported by the Research Foundation Flanders (FWO) (postdoctoral research fellowship: FWO13/PDO/191).

\section{LITERATURE}

[1] WHO: Global recommendations on physical activity for health. Geneva, World Health Organisation 2010.

[2] WHO: Global Health Risks Mortality. and burden of disease attributable to selected major risks. 2009. 
[3] Lock K, Pomerleau J, Causer L, Altmann D, McKee M: The global burden of disease attributable to low consumption of fruit and vegetables: implications for the global strategy on diet. Bulletin of the World Health Organisation 2005, 83(2):100-108.

[4] WHO: Diet, Nutrition and the prevention of Chronic diseases, Report of Joint WHO/FAO Expert Consultation. 2003.

[5] Haskell WL, Lee IM, Pate RR, Powell KE, Blair SN, Franklin BA, Macera CA, Heath GW, Thompson PD, Bauman A. Physical activity and public health: updated recommendation for adults from the American College of Sports Medicine and the American Heart Association. Med Sci Sports Exerc 2007, 39:1423-1434.

[6] Tafforeau J. Lichaamsbeweging. Gezondheidsenquête [Physical Activity. Health Interview Survey] België (Belgium). 2008.

[7] Vandevijvere S, De Vriese S, Huybrechts I, Moreau M, Temme E, De Henauw S, De Backer G, Kornitzer M, Leveque A, Van Oyen $\mathrm{H}$. The gap between food-based dietary guidelines and usual food consumption in Belgium, 2004. Public Health Nutr 2009, 12:423-431.

[8] Greaves CJ, Sheppard KE, Abraham C, Hardeman W, Roden M, Evans PH, Schwarz P, Group IS. Systematic review of reviews of intervention components associated with increased effectiveness in dietary and physical activity interventions. BMC Public Health 2011, 11:119.

[9] Broekhuizen K, Kroeze W, van Poppel MN, Oenema A, Brug J. A systematic review of randomized controlled trials on the effectiveness of computer-tailored physical activity and dietary behavior promotion programs: an update. Ann Behav Med 2012, 44:259-286.

[10] Lustria ML, Cortese J, Noar SM, Glueckauf RL. Computer-tailored health interventions delivered over the Web: review and analysis of key components. Patient Educ Couns 2009, 74:156-173.

[11] Maes S, Karoly P. Self-Regulation Assessment and Intervention in Physical Health and Illness: A Review. Appl Psychol Int Rev 2005, 54(2):267-299.

[12] Schwarzer R. Modeling Health Behavior Change: How to Predict and Modify the Adoption and Maintenance of Health Behaviors. Applied Psychology 2008, 57:1-29.

[13] Tones, K. and Tilford, S. Health Promotion: Effectiveness, Efficiency and Equity, 3rd edn., Nelson Thornes, Cheltenham, 2001.

[14] Bartholomew L, Parcel G, Kok G, Gottlieb N, Fernández M. Pretesting, Revising and Producing Program Components, in Planning Health Promotion Programs: An Intervention Mapping Approach, San Francisco: Jossey-Bass, 2011, pp. 443-448.

[15] Heart T, Kalderon E. Older adults: are they ready to adopt health-related ICT? Int J Med Inform 2013, 82:e209-231.

[16] Vandelanotte C: Acceptability and feasibility of a computer-tailored physical activity intervention using stages of change: project FAITH. Health Education Research 2003, 18:304-317.

[17] Spittaels H, De Bourdeaudhuij I, Vandelanotte C. Evaluation of a website-delivered computertailored intervention for increasing physical activity in the general population. Prev Med 2007, 44:209-217.

[18] van Genugten L, van Empelen P, Flink I, Oenema A. Systematic development of a self-regulation weight-management intervention for overweight adults. BMC Public Health 2010, 10:649.

[19] Springvloet L, Lechner L, \& Oenema A. Planned development and evaluation protocol of two versions of a web-based computer-tailored nutrition education intervention aimed at adults, including cognitive and environmental feedback. BMC Public Health 2014, 14: 47.

[20] Vandelanotte C, De Bourdeaudhuij I, Philippaerts R, Sjöström M, Sallis J. Reliability and Validityof a Computerized and Dutch Versionof the International Physical Activity Questionnaire (IPAQ). Journal of Physical Activity and Health 2005, 2: 6-75.

[21] Spittaels H, De Bourdeaudhuij I, Brug J, Vandelanotte C. Effectiveness of an online computertailored physical activity intervention in a real-life setting. Health Educ Res 2007, 22:385-396.

[22] VIG: Gezondheidsbevordering op het werk. Resultaten en verslag van de productevaluatie Voeding: fruittest, groententest en vochttest. [Health promotion at work. Results and report of product evaluation Nutrition: fruit and vegetable test] 2004. 
[23] Haerens L, Deforche B, Vandelanotte C, Maes L, De Bourdeaudhuij I: Acceptability, feasibility and effectiveness of a computer-tailored physical activity intervention in adolescents. Patient Educ Couns 2007, 66:303-310.

[24] Vandelanotte C, De Bourdeaudhuij I, Brug J: Acceptability and feasibility of an interactive computer-tailored fat intake intervention in Belgium. Health Promot Int 2004, 19:463-470.

[25] De Vet E, Oenema A, Sheeran P, Brug J: Should implementation intentions interventions be implemented in obesity prevention: the impact of if-then plans on daily physical activity in Dutch adults. Int J Behav Nutr Phys Act 2009, 6:11.

[26] Michie S, Abraham C, Whittington C, McAteer J. Effective Techniques in Healthy Eating and Physical Activity Interventions: A Meta-Regression. Health Psychology 2009, 28, 6: 690-701.

[27] Schneider F, van Osch LA, Kremers SP, Schulz DN, van Adrichem MJ, de Vries H. Optimizing diffusion of an online computer tailored lifestyle program: a study protocol. BMC Public Health 2011, 11:480.

[28] Schneider F. Reach out and touch? Improving reach and use of an Internet-delivered lifestyle intervention. 2003, Maastricht University, School for Public Health and Primary Care: CAPHRI, Department of Health Promotion.

[29] Brouwer W, Oenema A, Crutzen R, Nooijer Jd, Vries NKd, Brug J. What makes people decide to visit and use an internet-delivered behavior-change intervention?: A qualitative study among adults. Health Education 2009, 109:460-473.

[30] Sciamanna CN, Marcus BH, Goldstein MG, Lawrence K, Swartz S, Bock B, Graham AL, Ahern DK. Feasibility of incorporating computertailored health behaviour communications in primary care settings. 2004, Informatics in Primary Care, 12: 40-48.

[31] Ampt AJ, Amoroso C, Harris MF, McKenzie SH, Rose VK, Taggart JR. Attitudes, norms and controls influencing lifestyle risk factor management in general practice. BMC Fam Pract 2009, 10:59.

[32] Lawlor D, Keen S, Neal R. Can general practitioners influence the nation's health through a population approach to provision of lifestyle advice? Britisch Journal of General Practice 2012, 50:455-459.

[33] Sallis JF, Saelens BE. Assessment of physical activity by self-report: status, limitations, and future directions. Res Q Exerc Sport 2000, 71:S1-14. 


\section{TABLES}

Table 1: Baseline characteristics for the total sample and the four conditions separately.

\begin{tabular}{|c|c|c|c|c|c|}
\hline & $\begin{array}{l}\text { Total group } \\
(n=529)\end{array}$ & $\begin{array}{l}\text { Intervention } \\
\text { Physical } \\
\text { Activity } \\
(\mathbf{n}=158)\end{array}$ & $\begin{array}{l}\text { Intervention } \\
\text { Fruit intake } \\
(n=166)\end{array}$ & $\begin{array}{l}\text { Intervention } \\
\text { Vegetable } \\
\text { intake } \\
(\mathbf{n}=50)\end{array}$ & Control group \\
\hline Age (years) & $31.6 \pm 13.1$ & $30.5 \pm 12.6^{*}$ & $28.1 \pm 10.9 *$ & $33.8 \pm 13.4$ & $36.9 \pm 14.6$ \\
\hline Gender ( $\%$ male $)$ & 40.0 & $44.5^{*}$ & $47.8^{*}$ & 33.3 & 28.9 \\
\hline $\begin{array}{l}\text { Education level (\% high } \\
\text { university or college) }\end{array}$ & 78.7 & 73.6 & $75.8 *$ & 66.6 & 63.9 \\
\hline \multicolumn{6}{|l|}{$\begin{array}{l}\text { Not meeting } \\
\text { recommendations }(\%)\end{array}$} \\
\hline Fruit & & - & $95.7 *$ & - & 82.6 \\
\hline Vegetables & & - & - & 97.9 & 91.0 \\
\hline Physical Activity & & 52.3 & - & - & 48.4 \\
\hline \multicolumn{6}{|l|}{ Physical Activity level } \\
\hline $\begin{array}{l}\text { Total Physical Activity } \\
\text { (min per day) }\end{array}$ & & $63.6 \pm 58.5^{*}$ & - & - & $80.6 \pm 68.3$ \\
\hline $\begin{array}{l}\text { Moderate- and vigorous- } \\
\text { intensity (min per day) }\end{array}$ & & $41.3 \pm 45.2^{*}$ & - & - & $50.4 \pm 57.9$ \\
\hline Fruit intake (Portion/day) & & - & $0.8 \pm 0.7 *$ & - & $1.1 \pm 1.1$ \\
\hline $\begin{array}{l}\text { Vegetable intake } \\
\text { (Gram/day) }\end{array}$ & & - & - & $137.1 \pm 88.1$ & $141.1 \pm 125.4$ \\
\hline
\end{tabular}


1 Table 2: Acceptance and feasibility of module 1: differences between age groups and educational levels.

\begin{tabular}{|c|c|c|c|c|c|c|c|c|c|}
\hline \multirow[t]{2}{*}{ Items } & \multirow{2}{*}{$\begin{array}{l}\text { Total } \\
\text { sample } \\
\text { mean } \pm \\
\text { SD }\end{array}$} & \multirow{2}{*}{$\begin{array}{l}\text { Agree/ } \\
\text { Totally } \\
\text { agree } \\
(\%)\end{array}$} & \multicolumn{2}{|l|}{$\begin{array}{l}\text { age group } \\
\text { mean } \pm \mathrm{SD}\end{array}$} & \multicolumn{2}{|c|}{$\begin{array}{l}\text { educational level } \\
\text { mean } \pm \text { SD }\end{array}$} & \multicolumn{3}{|c|}{ Intervention module } \\
\hline & & & $<40$ year & $>40$ year & $\begin{array}{l}\text { Low } \\
\text { education }\end{array}$ & $\begin{array}{l}\text { High } \\
\text { education }\end{array}$ & PA & Fruit & Vegetables \\
\hline \multicolumn{10}{|l|}{$\begin{array}{l}\text { Questionnaire: I think the } \\
\text { questionnaire ... }\end{array}$} \\
\hline Was easy to understand & $3.5 \pm 0.61$ & 96.9 & $3.5 \pm 0.56$ & $3.5 \pm 0.77$ & $3.3 \pm 0.69 * *$ & $3.5 \pm 0.55^{* *}$ & $3.4 \pm 0.6$ & $3.6 \pm 0,5$ & $3.4 \pm 0.8$ \\
\hline Had clear answer options & $3.4 \pm 0.68$ & 91.6 & $3.5 \pm 0.63 * *$ & $3.2 \pm 0.85 * *$ & $3.4 \pm 0.78$ & $3.4 \pm 0.65$ & $3.4 \pm 0.6$ & $3.5 \pm 0.6$ & $3.3 \pm 0.9$ \\
\hline Went with clear instructions & $3.4 \pm 0.61$ & 96.4 & $3.5 \pm 0.55$ & $3.3 \pm 0.81$ & $3.4 \pm 0.77$ & $3.5 \pm 0.55$ & $3.4 \pm 0.6$ & $3.5 \pm 0.5$ & $3.3 \pm 0.8$ \\
\hline Had too long questions & $2.8 \pm 0.89$ & 11.5 & $2.7 \pm 0.88$ & $2.7 \pm 0.85$ & $2.8 \pm 0.86$ & $2.6 \pm 0.88$ & $2.9 \pm 0.7$ & $2.9 \pm 0.9$ & $3.1 \pm 0.5$ \\
\hline Had too many questions & $3.0 \pm 0.76$ & 5.8 & $3.0 \pm 0.78$ & $3.0 \pm 0.66$ & $3.0 \pm 0.74$ & $2.9 \pm 0.78$ & $2.5 \pm 0.9 * *$ & $2.8 \pm 0.8 * *$ & $2.7 \pm 0.8$ \\
\hline \multicolumn{10}{|l|}{$\begin{array}{l}\text { Personal advice: I think } \\
\text { the personal advice ... }\end{array}$} \\
\hline Was personally relevant & $2.9 \pm 0.62$ & 84.5 & $2.9 \pm 0.65$ & $3.0 \pm 0.56$ & $2.9 \pm 0.56$ & $3.0 \pm 0.65$ & $2.8 \pm 0.7$ & $3.0 \pm 0.6$ & $2.8 \pm 0.7$ \\
\hline Was interesting & $2.9 \pm 0.72$ & 79.1 & $2.8 \pm 0.78 * *$ & $3.0 \pm 0.47 * *$ & $3.0 \pm 0.56$ & $2.8 \pm 0.78$ & $2.8 \pm 0.8$ & $3.0 \pm 0.7$ & $2.8 \pm 0.7$ \\
\hline Was clear & $2.9 \pm 0.72$ & 83.3 & $2.9 \pm 0.74$ & $3.0 \pm 0.64$ & $3.0 \pm 0.52$ & $2.9 \pm 0.77$ & $2.8 \pm 0.7$ & $3.0 \pm 0.8$ & $3.0 \pm 0.4$ \\
\hline Was understandable & $3.1 \pm 0.54$ & 59.5 & $3.1 \pm 0.57$ & $3.1 \pm 0.44$ & $3.1 \pm 0.42$ & $3.2 \pm 0.58$ & $3.0 \pm 0.6$ & $3.2 \pm 0.5$ & $3.1 \pm 0.4$ \\
\hline Has taught me something & $2.6 \pm 0.88$ & 61.1 & $2.5 \pm 0.90 * *$ & $2.9 \pm 0.72 * *$ & $2.8 \pm 0.65^{* *}$ & $2.5 \pm 0.94 * *$ & $2.4 \pm 0.9$ & $2.7 \pm 0.8$ & $2.6 \pm 0.9$ \\
\hline Was motivating & $2.6 \pm 0.94$ & 59.5 & $2.5 \pm 0.98 * * *$ & $3.0 \pm 0.66 * * *$ & $2.8 \pm 0.80^{*}$ & $2.5 \pm 0.99 *$ & $2.4 \pm 0.9$ & $2.7 \pm 0.9$ & $2.8 \pm 0.9$ \\
\hline Was directive & $2.8 \pm 0.78$ & 10.3 & $2.8 \pm 0.77$ & $2.7 \pm 0.86$ & $2.8 \pm 0.70$ & $2.8 \pm 0.82$ & $2.9 \pm 0.8$ & $2.7 \pm 0.8$ & $2.8 \pm 0.7$ \\
\hline Was too long & $2.9 \pm 0.70$ & 5.9 & $2.9 \pm 0.72$ & $2.9 \pm 0.68$ & $2.8 \pm 0.68^{*}$ & $2.9 \pm 0.71^{*}$ & $2.9 \pm 0.8$ & $2.9 \pm 0.7$ & $3.0 \pm 0.5$ \\
\hline \multicolumn{10}{|l|}{ Extra information: } \\
\hline $\begin{array}{l}\text { I think it is good you can } \\
\text { choose which info to read }\end{array}$ & $3.3 \pm 0.49$ & 100 & $3.4 \pm 0.51$ & $3.3 \pm 0.47$ & $3.3 \pm 0.50$ & $3.35 \pm 0.49$ & $3.1 \pm 0.4$ & $3.5 \pm 0.5$ & $3.3 \pm 0.5$ \\
\hline $\begin{array}{l}\text { The extra information was } \\
\text { useful }\end{array}$ & $3.0 \pm 0.72$ & 84.6 & $3.1 \pm 0.83$ & $2.9 \pm 0.54$ & $3.1 \pm 0.60$ & $3.0 \pm 0.79$ & $2.8 \pm 0.5$ & $3.2 \pm 0.9$ & $3.0 \pm 0.1$ \\
\hline \multicolumn{10}{|l|}{$\begin{array}{l}\text { Action plan: I think the } \\
\text { action plan }\end{array}$} \\
\hline $\begin{array}{l}\text { Includes the necessary } \\
\text { things }\end{array}$ & $2.5 \pm 0.84$ & 64.3 & $2.5 \pm 0.86$ & $2.7 \pm 0.76$ & $2.8 \pm 0.71 * *$ & $2.5 \pm 0.87 * *$ & $2.4 \pm 0.9$ & $2.7 \pm 0.7$ & $2.5 \pm 0.9$ \\
\hline Is extra motivating & $2.5 \pm 0.93$ & 61.5 & $2.5 \pm 0.99 * *$ & $2.8 \pm 0.64 * *$ & $2.7 \pm 0.86$ & $2.5 \pm 0.96$ & $2.3 \pm 0.9 * *$ & $2.7 \pm 0.8 * *$ & $2.6 \pm 1.1$ \\
\hline Has a an attractive lay-out & $2.7 \pm 0.84$ & 72.0 & $2.6 \pm 0.86$ & $2.8 \pm 0.72$ & $2.9 \pm 0.58 * *$ & $2.6 \pm 0.89^{* *}$ & $2.5 \pm 0.9^{*}$ & $2.7 \pm 0.8 * *$ & $3.1 \pm 0.6^{*}$ \\
\hline Is easy to understand & $3.1 \pm 0.53$ & 93.4 & $3.1 \pm 0.57$ & $3.1 \pm 0.34$ & $3.1 \pm 0.46$ & $3.1 \pm 0.55$ & $3.1 \pm 0.6$ & $3.1 \pm 0.5$ & $3.2 \pm 0.6$ \\
\hline
\end{tabular}




\begin{tabular}{|c|c|c|c|c|c|c|c|c|c|}
\hline Is personally relevant & $2.8 \pm 0.78$ & 76.3 & $2.8 \pm 0.84$ & $2.9 \pm 0.44$ & $2.8 \pm 0.63$ & $2.8 \pm 0.82$ & $2.7 \pm 0.8$ & $2.8 \pm 0.8$ & $2.9 \pm 0.7$ \\
\hline Is feasible to reach & $3.2 \pm 0.50$ & 96.7 & $3.2 \pm 0.51$ & $3.2 \pm 0.46$ & $3.2 \pm 0.48$ & $3.2 \pm 0.51$ & $3.1 \pm 0.5$ & $3.2 \pm 0.4$ & $3.1 \pm 0.6$ \\
\hline $\begin{array}{l}\text { I think there were good } \\
\text { questions to make the plan }\end{array}$ & $2.9 \pm 0.63$ & 85.7 & $2.9 \pm 0.67$ & $3.0 \pm 0.43$ & $3.0 \pm 0.46$ & $2.9 \pm 0.67$ & $2.7 \pm 0.7 *$ & $3.1 \pm 0.5^{*}$ & $3.0 \pm 0.4$ \\
\hline $\begin{array}{l}\text { I think there were good tips } \\
\text { to make the plan }\end{array}$ & $2.8 \pm 0.76$ & 77.4 & $2.8 \pm 0.78$ & $2.9 \pm 0.70$ & $2.9 \pm 0.70$ & $2.8 \pm 0.78$ & $2.7 \pm 0.8$ & $2.9 \pm 0.8$ & $2.9 \pm 0.7$ \\
\hline $\begin{array}{l}\text { I think it is good the plan } \\
\text { was sent to me }\end{array}$ & $3.1 \pm 0.65$ & 90.6 & $3.1 \pm 0.68$ & $3.1 \pm 0.41$ & $3.0 \pm 0.51^{*}$ & $3.1 \pm 0.66^{*}$ & $3.1 \pm 0.7$ & $3.2 \pm 0.7$ & $3.1 \pm 0.5$ \\
\hline I am going to print the plan & $1.9 \pm 1.22$ & 36.2 & $1.8 \pm 1.24$ & $2.1 \pm 1.11$ & $2.1 \pm 1.18$ & $1.8 \pm 1.23$ & $1.9 \pm 1.2$ & $1.9 \pm 1.2$ & $1.9 \pm 1.3$ \\
\hline I will live up to 'MyPlan' & $3.1 \pm 0.67$ & 86.3 & $3.0 \pm 0.69$ & $3.1 \pm 0.59$ & $3.1 \pm 0.51$ & $3.0 \pm 0.71$ & $2.9 \pm 0.7 *$ & $3.2 \pm 0.6^{*}$ & $3.1 \pm 0.6$ \\
\hline \multicolumn{10}{|l|}{ If-then plan: } \\
\hline $\begin{array}{l}\text { I think it is good that I could } \\
\text { make my own if-then plan }\end{array}$ & $2.8 \pm 0.92$ & 70.7 & $2.7 \pm 0.97$ & $2.9 \pm 0.70$ & $2.7 \pm 0.87$ & $2.8 \pm 0.94$ & $2.6 \pm 0.9 *$ & $3.0 \pm 0.8^{*}$ & $2.8 \pm 0.8$ \\
\hline $\begin{array}{l}\text { I had enough information to } \\
\text { make an if-then plan }\end{array}$ & $3.1 \pm 0.64$ & 89.0 & $3.1 \pm 0.66$ & $3.0 \pm 0.58$ & $3.0 \pm 0.62$ & $3.1 \pm 0.66$ & $3.0 \pm 0.7$ & $3.1 \pm 0.6$ & $3.1 \pm 0.7$ \\
\hline
\end{tabular}

2 A significant difference between the different groups (i.e. age, educational level, intervention module): $* \mathrm{p}<0.1 ; * * \mathrm{p}<0.05 ; * * * \mathrm{p}<0.001$

3

4

5

6 
Table 3: Evaluation of the second intervention module

\begin{tabular}{ll}
\hline Items & Answers (\%) \\
\hline Did you expect the evaluation of your health goals? (\% yes) & \\
Yes, I knew that I reached my goal & 44.4 \\
Yes, I knew that I did not reach my goal & 44.9 \\
No, I thought that I reached my goal & 6.2 \\
No, I thought that I did not reach my goal & 4.3 \\
How much do you agree with the following statements? (\% agree/totally agree) & \\
"I think it is good that I can evaluate if I reached my goals" & 84.3 \\
"The goal evaluation leads to extra motivation for goal pursuit" & 68.1 \\
Did you send your action plan to friends of family? (\% yes) & 24.7 \\
Did these friends or family supported you in pursuing your goal? (\% yes) & 64.9 \\
Did you monitor your behaviour? (\% yes) & 38.7 \\
\hline
\end{tabular}


Table 4: Intervention effect on fruit intake, vegetable intake and physical activity

\begin{tabular}{|c|c|c|c|c|c|}
\hline & \multicolumn{2}{|c|}{$\begin{array}{l}\text { Intervention } \\
\text { Fruit (80) } \\
\text { Vegetables (12) } \\
\text { Physical activity (45) }\end{array}$} & \multicolumn{2}{|c|}{$\begin{array}{l}\text { Control } \\
\text { Fruit (48) } \\
\text { Vegetables (53) } \\
\text { Physical activity (55) }\end{array}$} & \multirow[t]{2}{*}{$\mathbf{F}_{\text {Group x Time }}$} \\
\hline & $\begin{array}{l}\text { Pre } \\
M \pm \mathrm{SD}\end{array}$ & $\begin{array}{l}\text { Post } \\
M \pm \mathrm{SD}\end{array}$ & $\begin{array}{l}\text { Pre } \\
M \pm \mathrm{SD}\end{array}$ & $\begin{array}{l}\text { Post } \\
M \pm \mathrm{SD}\end{array}$ & \\
\hline $\begin{array}{l}\text { Fruit intake (Portion } \\
\text { per day) }\end{array}$ & $0.7 \pm 1.8$ & $1.6 \pm 1.9$ & $0.6 \pm 2.4$ & $1.0 \pm 2.1$ & $9.5 * *$ \\
\hline $\begin{array}{l}\text { Vegetable intake } \\
\text { (Average gram per day) }\end{array}$ & $124.4 \pm 1.9$ & $199.0 \pm 1.9$ & $91.9 \pm 2.3$ & $107.9 \pm 2.4$ & $3.0 *$ \\
\hline $\begin{array}{l}\text { Total Physical Activity } \\
\text { (min per week) }\end{array}$ & $231.1 \pm 2.4$ & $351.1 \pm 1.7$ & $308.1 \pm 2.9$ & $375.3 \pm 2.9$ & $5.6^{* *}$ \\
\hline $\begin{array}{l}\text { Moderate intensity PA } \\
\text { (min per week) }\end{array}$ & $157.4 \pm 2.5$ & $252.6 \pm 1.7$ & $252.6 \pm 2.6$ & $314.8 \pm 2.7$ & $2.9^{*}$ \\
\hline $\begin{array}{l}\text { Vigorous intensity PA } \\
\text { (min per week) }\end{array}$ & $67.1 \pm 2.4$ & $98.1 \pm 1.9$ & $127.1 \pm 2.3$ & $145.4 \pm 2.2$ & 0.2 \\
\hline
\end{tabular}


Figure 2: Intervention program

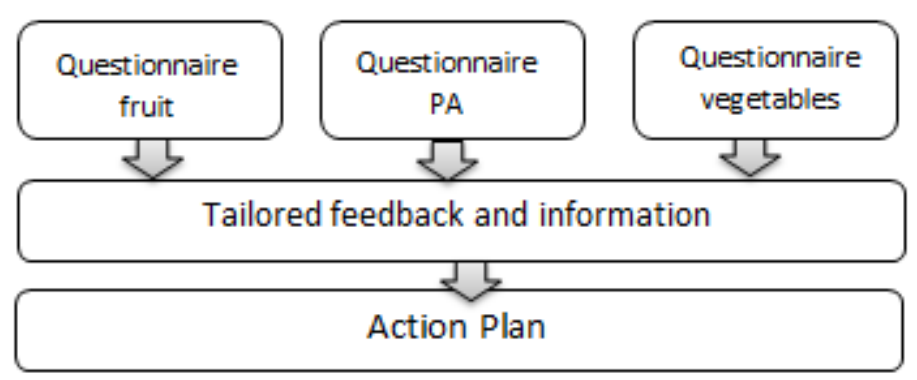

Email 1: action plan

Email 2: invitation for session 2

Iterative feedback and evaluation of action plan

Maintain action plan Adapt action plan

Email 3: action plan

Email 4: invitation for session 3

Iterative feedback and evaluation of action plan 
Figure 2 - My Action plan

Example of an action plan for physical activity

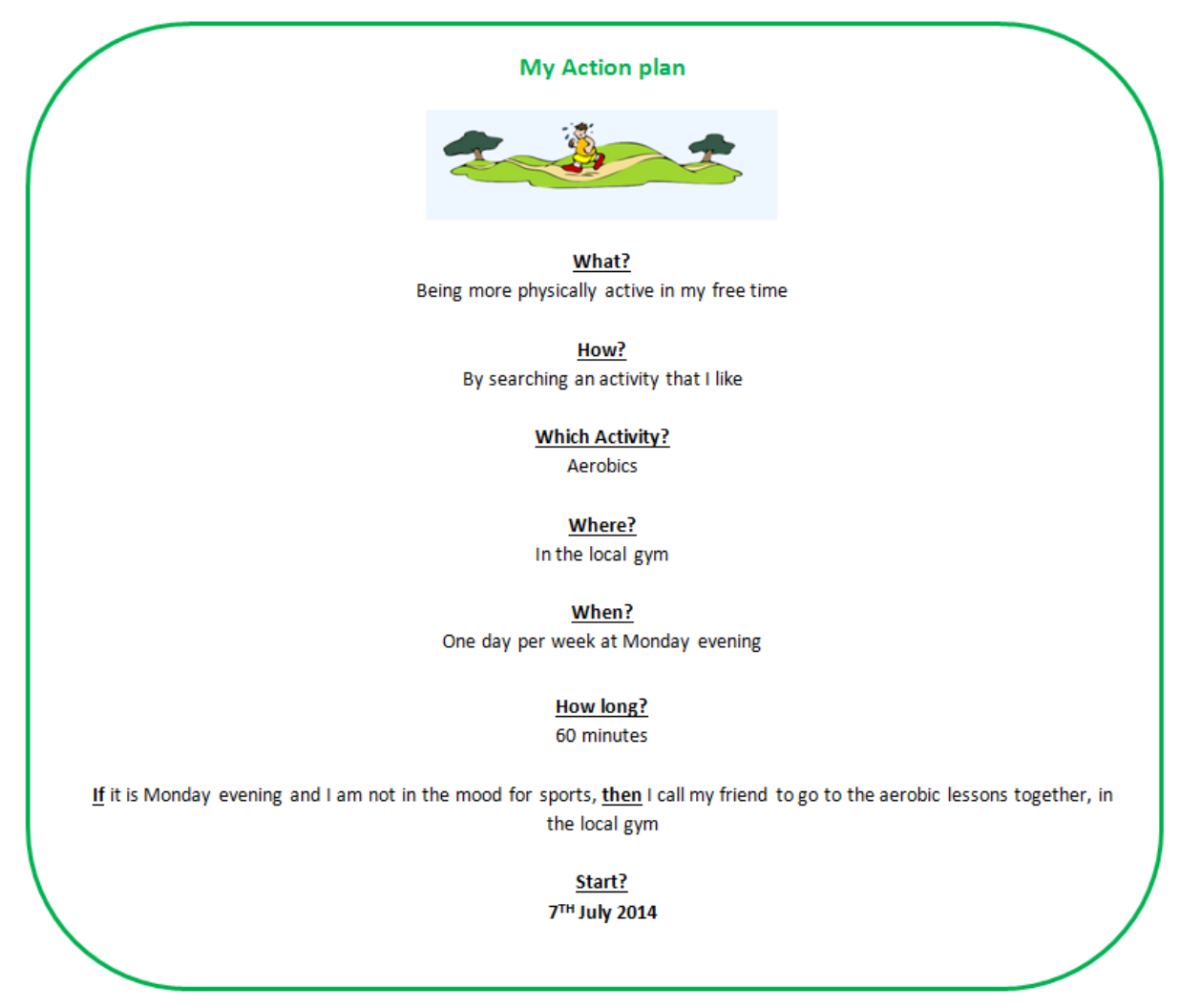

